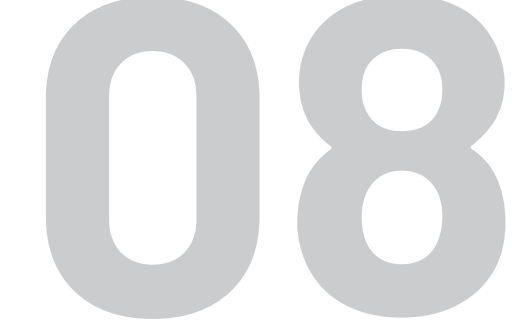

\title{
Evolución reciente de la inmigración marítima irregular en Canarias
}

Elaborado por DiRK GodenaU, Daniel BuraschI

y Vicente Manuel Zapata Hernández

La reciente intensificación de las migraciones marítimas irregulares que protagonizan la ruta atlántica a través de Canarias, con el fin de acceder al continente europeo desde el africano, coincide en el tiempo con el desarrollo de la pandemia por coronavirus e incorpora algunas novedades en relación con una corriente que viene estando presente en el devenir del archipiélago desde hace casi tres décadas. También ofrece muchas similitudes con la permanente manifestación de esta afluencia, pese a que la escasa planificación y debilidad de la respuesta articulada inicialmente para abordar su gestión integral, ha situado el fenómeno en el primer plano de la actualidad y el debate en la región. Y de esta manera, un contexto social de enorme incertidumbre debido a la crisis sanitaria y económica, el conocimiento directo y casi en directo del desenlace de muchas expediciones a través de las redes sociales, junto al desconcierto que transmite la gestión de esta movilidad pese a que sus cifras no son comparables a las de la década anterior, entre otros aspectos, plantean la necesidad de retomar su análisis con el objetivo de desentrañar sus actuales características y claves para su comprensión.

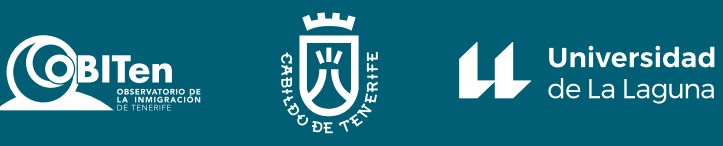




\section{Aclaración conceptual: ¿qué entendemos por inmigración irregular?}

La inmigración irregular es un tema altamente mediatizado y de relevancia social y política. Para referirse a las personas inmigrantes irregulares se utilizan diferentes términos como ilegal, indocumentado, clandestino o sin papeles; cada uno con implicaciones conceptuales, sociales y políticas diferentes (Echevarría, 2020). De hecho, como subrayan Cvajner y Sciortino (2010: 390) "detrás de la noción de migración irregular existe hoy en día un conjunto de marcos interpretativos, estereotipos, sabiduría popular, iconos y eslóganes que la convierten en parte de un complejo discurso simbólico". El término ilegal, por ejemplo, además de ser incorrecto desde punto de vista conceptual, puesto que ninguna persona es ilegal, es un concepto que contribuye a deshumanizar, criminalizar y excluir a las personas migrantes, legitimando, a menudo, medidas punitivas y discriminatorias (Düvell, 2011).

Siguiendo a la Organización Internacional de las Migraciones podemos definir a los inmigrantes irregulares como "las personas que se desplazan al margen de las normas de los Estados de envío, de tránsito o receptor. [...] Desde el punto de vista de los países de destino significa que es ilegal el ingreso, la estadía o el trabajo, es decir, que el migrante no tiene la autorización necesaria ni los documentos requeridos por las autoridades de inmigración para ingresar, residir o trabajar en un determinado país. Desde el punto de vista de los países de envío la irregularidad se observa en los casos en que la persona atraviesa una frontera internacional sin documentos de viaje o pasaporte válido o no cumple con los requisitos administrativos exigidos para salir del país" (OIM, 2006: 40).

A partir de esta definición, un primer aspecto a tener en cuenta es que el adjetivo irregular no hace referencia a una característica de las personas migrantes, sino a una relación entre un migrante o un grupo de migrantes y un conjunto de normas establecidas por un Estado o un conjunto de Estados (De Genova, 2002).

El término, además, puede hacer referencia a realidades diferentes. Por un lado, el incumplimiento por parte de los migrantes de las normas de entrada; por ejemplo, se puede tratar de personas que han accedido a España sin la autorización necesaria como en el caso de las migraciones marítimas irregulares. Por el otro, la estancia irregular; por ejemplo, personas que han entrado regularmente con un visado de turista y que se han quedado en el país más allá del tiempo permitido, o personas que por distintos motivos no han podido renovar el permiso de residencia por encontrarse desempleadas. Pueden existir situaciones muy variadas, con implicaciones jurídicas, sociales y económicas muy diferentes.

La separación entre regular e irregular no es siempre clara y existen espacios de ambivalencia jurídica, momentos de irregularidad que dependen de los trámites administrativos. Una misma persona puede pasar también por diferentes etapas de regularidad e irregularidad a lo largo de su trayectoria migratoria (Echevarría, 2020).

Los trayectos geográficos de la emigración africana al continente europeo son variados en términos de sus puntos de inicio o países de salida; no todos ellos africanos, puesto que África también es lugar de tránsito para personas originarias de otros continentes. Asimismo son diversas las rutas seguidas hasta abandonar el continente africano, con gran parte de las personas dirigiéndose a las costas del Mediterráneo y solo en menor medida a los bordes del África occidental. E igualmente cabe considerar el medio marítimo o terrestre utilizado para cruzar la frontera europea. Las Islas Canarias son un ejem- 
plo de los territorios insulares de Europa que se encuentran en los espacios intersticiales entre continentes, algunos de los cuales (la minoría) están más expuestos que otros a las llegadas de los flujos migratorios por vía marítima.

Esta parte del trayecto migratorio, la travesía marítima, cuenta con algunas particularidades: primero, se trata de un medio, el marítimo, que exige medios específicos de transporte (embarcaciones); segundo, de lo anterior se desprende la elevada probabilidad de agruparse las personas migrantes como pasajeros de una embarcación; tercero, la navegación precisa, especialmente en trayectos arriesgados, de conocimientos específicos, lo que convierte la presencia de un patrón con pericia suficiente en un valor estratégico para minimizar la probabilidad de naufragio; cuarto, el control de los espacios marítimos cuenta con retos tecnológicos específicos (radares de vigilancia, medios aéreos, embarcaciones). No es que sea necesariamente más difícil el control de las áreas marítimas (en comparación con las terrestres), pero sí es una tarea con atributos propios.

La posición geoestratégica de las islas en las rutas marítimas se deriva del hecho de pertenecer a países continentales (destinos de la migración), por lo que arribar a una de ellas supone haber entrado en espacio europeo (comunitario). Sin embargo, la probabilidad de detección de la llegada o permanencia en espacios insulares es elevada y, a su vez, la posibilidad de continuar el viaje hacia el continente de forma irregular es reducida (por la necesidad de utilizar el transporte colectivo, aéreo o marítimo, mucho más controlado que la continuidad terrestre). Las islas solo son atractivas como áreas de tránsito si después de la intercepción se cuenta con la posibilidad de continuar (o ser derivado) hacia espacios continentales (Godenau, 2012).

\section{Las Islas Canarias en la red de rutas}

\subsection{Evolución de las rutas migratorias África-UE}

La ruta atlántica de las migraciones marítimas irregulares a través de las Islas Canarias forma parte de un conjunto de itinerarios que canalizan una fracción de la emigración africana a Europa. Los datos sobre estas rutas no incluyen a las personas africanas que entran en la Unión Europea con permiso, ni tampoco aquéllas que obtienen acceso irregular por otras vías (ejemplo, falsificación de documentos).

La evolución general de estas rutas durante los años 2018 a 2020 se caracteriza por las siguientes tendencias: a) el número total de interceptaciones en su conjunto ha descendido claramente después de 2018 (ver mapa 1); b) esta tendencia contractiva también se manfiesta en la ruta mediterránea occidental que conecta con la España peninsular y Baleares (Frontex, 2020: 8); c) en cambio, la ruta canaria experimenta un crecimiento sustancial (Frontex, 2020: 26); d) el número de personas adicionales que llega por la ruta canaria era inferior a la reducción de la mediterránea durante el año 2019, pero en 2020 el incremento de la ruta atlántica empieza a ser superior a la reducción en la ruta mediterránea. Como muestra el gráfico 1, la ruta atlántica ha ocupado durante los últimos años una posición de escaso peso en comparación con las restantes, observación compatible con las elevadas tasas de crecimiento en el número de llegadas a Canarias, particularmente en 2020. 
Mapa 1

Las rutas de la migración irregular hacia Europa en el año 2019.

Fuente Frontex (2020: 24).

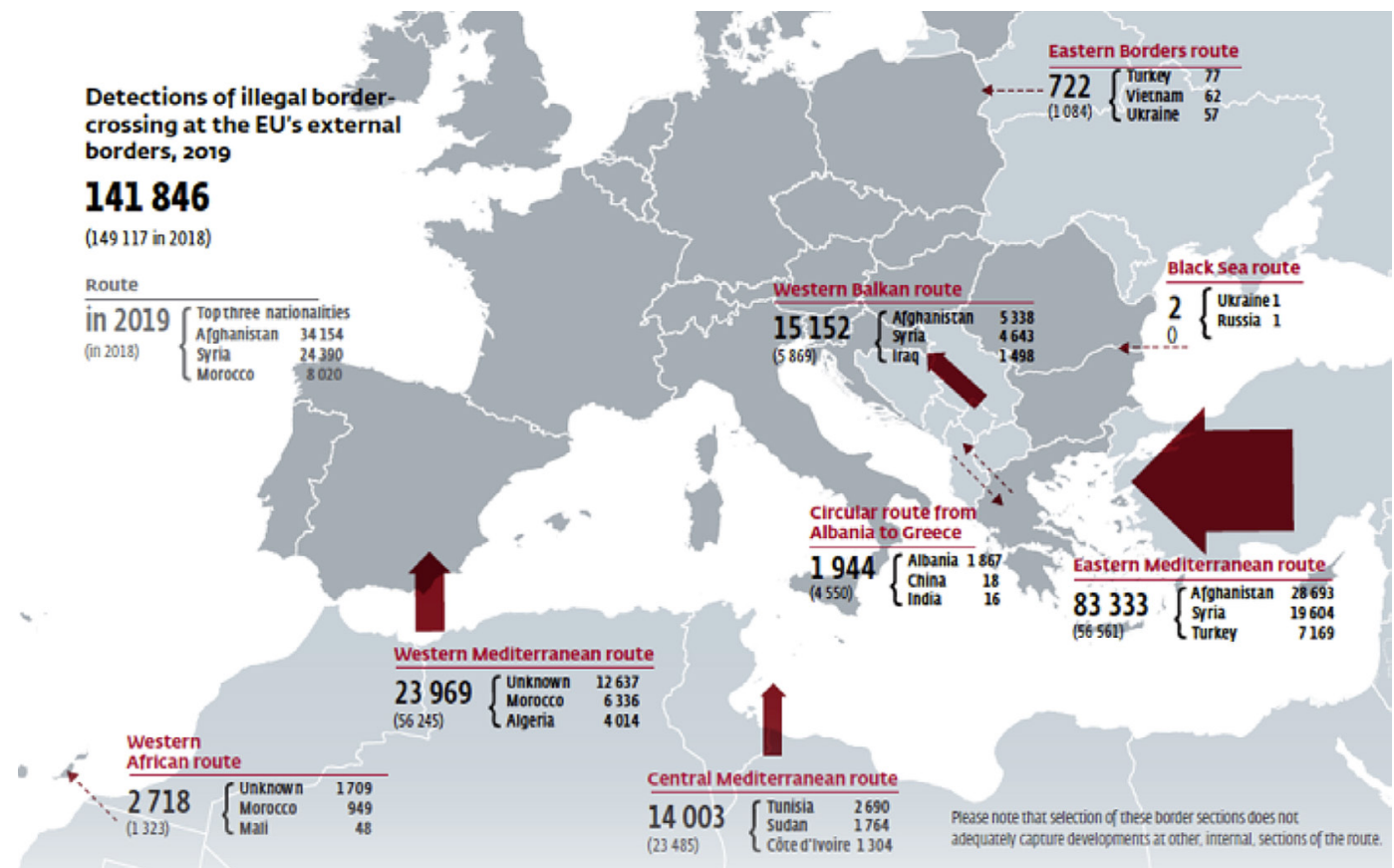

Gráfico 1

Número de detecciones

de personas en

travesías marítimas

irregulares según ruta

entre 2018 y 2020.

Fuente

Frontex.

Elaboración propia.

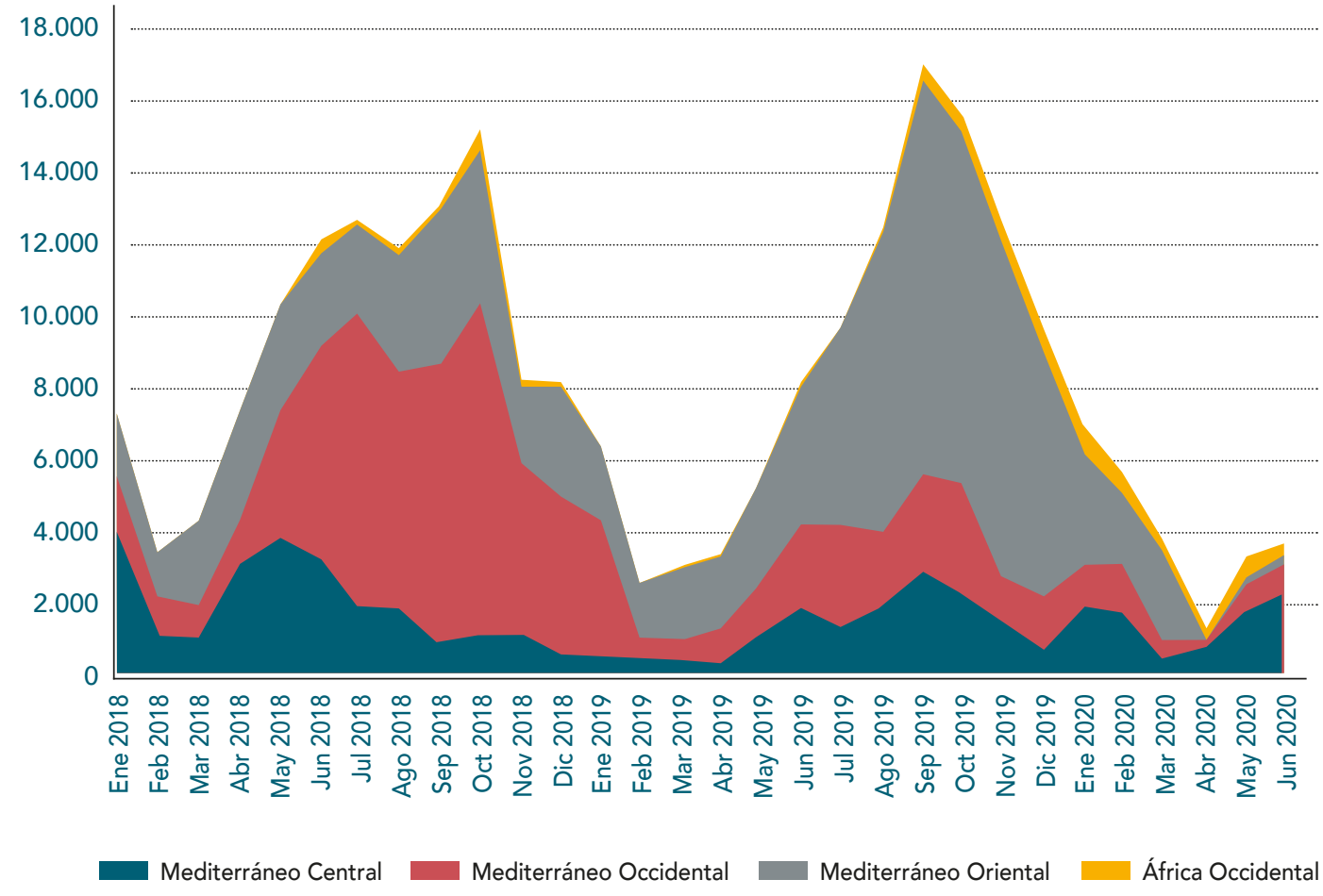

El gráfico 2 muestra este incremento sustancial en el número de cruces marítimos irregulares de frontera que se detectaron entre enero de 2018 y junio de 2020, incremento que ha supuesto un aumento en el peso de la ruta atlántica en el conjunto de las rutas marítimas.

Si a principio de 2018 este peso era inferior al 1\%, durante los primeros ocho meses de 2020 ya supera el 6\%. Este ascenso es resultado de la combinación de un mayor número de llegadas por esta ruta y de la contracción del total de interceptaciones marítimas entre África y Europa. 


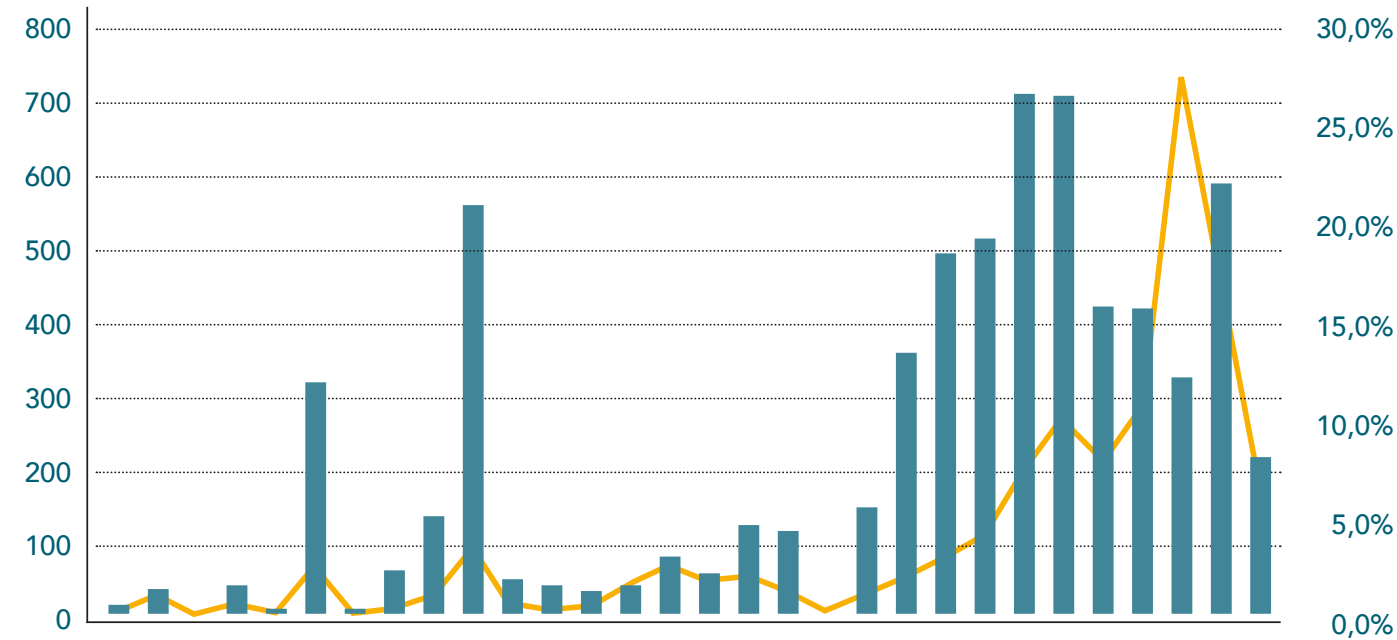

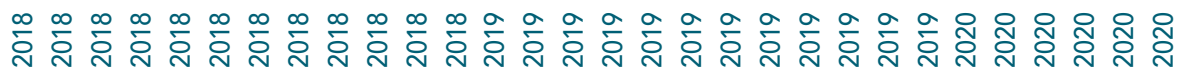

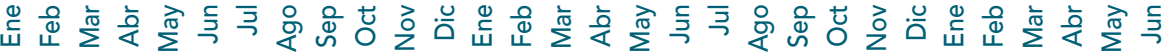

N..$^{\circ}$ interceptaciones

Peso ruta África Occidental (eje derecho)

\section{Gráfico 2}

Número de detecciones de personas en cruce marítimo irregular de frontera en la ruta del África Occidental y peso de las rutas marítimas entre África y Europa entre 2018 y 2020 (\%).

\section{Fuente}

Frontex.

Elaboración propia.
En la ruta del África Occidental, las estadísticas elaboradas por Frontex indican un elevado porcentaje de personas interceptadas cuya nacionalidad se desconoce (el $55,6 \%$ en el periodo enero 2018 a agosto 2020)' ${ }^{1}$. Entre las personas restantes, con nacionalidad conocida, destaca Marruecos (tabla 1), con un 30,6\%. El peso de este país limítrofe en las llegadas es muy elevado hasta julio de 2019 y luego desciende rápidamente por el incremento de los orígenes subsaharianos. Este patrón de nacionalidades no se debe confundir con los países de salida de las embarcaciones, porque bajo este criterio geográfico de los puntos de salida del continente africano, todavía no se observa un claro desplazamiento hacia países más al sur como Senegal (Frontex, 2020: 26), lo que a su vez incide en la duración de las travesías y las embarcaciones utilizadas.

\begin{tabular}{l|c|c}
\hline Nacionalidad & Personas interceptadas & $\%$ \\
\hline Subsaharianos sin especificar & 3.593 & 53,3 \\
\hline Marruecos & 2.064 & 30,6 \\
\hline Mali & 349 & 5,2 \\
\hline Senegal & 223 & 3,3 \\
\hline Desconocido & 152 & 2,3 \\
\hline Costa de Marfil & 103 & 1,5 \\
\hline Gambia & 96 & 1,4 \\
\hline Guinea & 89 & 1,3 \\
\hline Comoras & 25 & 0,4 \\
\hline Guinea-Bissau & 17 & 0,3 \\
\hline
\end{tabular}

1 Es probable que el conocimiento de los orígenes de las personas migrantes sea mayor entre las entidades que gestionan la recepción de estas personas. La tendencia general parece apuntar a un creciente peso de los orígenes subsaharianos, con particular aumento de Mali en fechas recientes, y que, incluso, la propensión de las personas migrantes a llevar documentación puede estar creciendo en un contexto de bajas probabilidades de devolución, por su posterior utilidad potencial en la continuación de su periplo migratorio.
Tabla 1

Nacionalidades de las personas interceptadas en cruce marítimo irregular en la ruta atlántica vía Islas Canarias entre enero de 2018 y agosto de 2020 (\%).

\section{Fuente}

Frontex.

Elaboración propia. 


\begin{tabular}{l|c|c}
\hline Nacionalidad & Personas interceptadas & $\%$ \\
\hline Argelia & 11 & 0,2 \\
\hline Camerún & 4 & 0,1 \\
\hline Bangladesh & 3 & 0,0 \\
\hline Mauritania & 3 & 0,0 \\
\hline Burkina Faso & 2 & 0,0 \\
\hline Sierra Leona & 1 & 0,0 \\
\hline Congo (Brazzaville) & 1 & 0,0 \\
\hline Gabón & 1 & 0,0 \\
\hline Libia & 1 & 0,0 \\
\hline Etiopía & $\mathbf{6 . 7 4 0}$ & 0,0 \\
\hline Total & & 100,0 \\
\hline
\end{tabular}

¿Por qué ahora un repunte en la ruta canaria? Resulta imposible cuantificar el peso de los diversos factores causantes de este cambio, pero se puede establecer un ranking de las causas principales: primero, los cambios en las permeabilidades relativas en las distintas rutas, con una mayor impermeabilización de la mediterránea occidental a partir de la segunda mitad de 2019; segundo, la relajación en los esfuerzos de cooperación en el control de la costa africana occidental; tercero, un aumento de la inestabilidad política y económica en determinados países de origen de la emigración subsahariana, como por ejemplo Mali, y de éste en su relación con Senegal y Burkina Faso; cuarto, un fenómeno de causación acumulativa en la reactivación de la ruta atlántica²; quinto, y relacionado con lo anterior, bajos porcentajes de devolución a los países de origen.

En este sentido, cabe señalar que las personas oriundas de Mali son mayoritarias en las expediciones procedentes de los países subsaharianos en la etapa más reciente, según se desprende de las entrevistas realizadas a personas que forman parte de los dispositivos de acogida. Integrarían en buena medida el colectivo de las que la estadística registra como Subsaharianos sin especificar. Serían el contingente más numeroso de inmigrantes junto a los marroquíes, con la diferencia de que estos llegan en grupos más reducidos pero frecuentes; y las embarcaciones procedentes de destinos más meridionales, con más ocupantes pero espaciadas en el tiempo. Con todo, las previsiones recogidas apuntan a la intensificación de este último flujo durante el trimestre final del año, cuando las corrientes atlánticas a partir del paralelo 20 (Nouadhibou) hacia el norte son menos peligrosas que en los meses centrales del verano (Vélez, 2015).

2 En el ámbito de las teorías migratorias se diferencia entre las que explican el inicio del proceso (y de las rutas) y las que explican su consolidación y crecimiento durante un periodo determinado. Entre los factores que inciden en esta causación acumulativa a lo largo del tiempo destacan la creación y comunicación de información sobre cómo organizar el proyecto migratorio (efecto imitación), el establecimiento de estructuras organizativas (véase la bibliografía sobre los mercados migratorios; López Sala y Godenau, 2017) y los beneficios de los vínculos ya establecidos con familiares y amistades en los lugares de destino (redes migratorias). 


\subsection{Factores de riesgo en la ruta atlántica del África Occidental}

La ruta atlántica es sumamente peligrosa, según refieren muchas personas y organizaciones especializadas, sobre todo cuando las salidas se realizan de puntos más meridionales (Vélez, 2012), porque el brazo de mar que con frecuencia deben salvar las expediciones es extenso y sus condiciones no son las más favorables para la navegación de embarcaciones que no fueron concebidas para este tipo de traslados. Los aproximadamente $110 \mathrm{~km}$ que separan las costas de Tarfaya, en el Sáhara Occidental, del punto más próximo del archipiélago canario, se pueden alargar hasta los 1.500 km desde el litoral de Senegal ${ }^{3}$. Las maniobras de llegada además no siempre se efectúan en las mejores condiciones de sus pasajeros, puesto que, a menudo, pasan muchos días de singladura que merman sus capacidades físicas y mentales y son recogidos con graves síntomas de agotamiento y desorientación.

\begin{tabular}{|c|c|c|c|c|}
\hline Año & Mes & Fallecidas & Desaparecidas & $\begin{array}{l}\text { Total fallecidas } \\
\text { y desaparecidas }\end{array}$ \\
\hline \multirow{7}{*}{2019} & Marzo & & 19 & 19 \\
\hline & Mayo & 3 & 1 & 4 \\
\hline & Julio & 7 & 4 & 11 \\
\hline & Agosto & 1 & 22 & 23 \\
\hline & Octubre & 6 & 1 & 7 \\
\hline & Noviembre & 9 & 2 & 11 \\
\hline & Diciembre & 70 & 40 & 110 \\
\hline \multirow{8}{*}{2020} & Enero & 2 & & 2 \\
\hline & Febrero & 5 & 21 & 26 \\
\hline & Marzo & 1 & 21 & 22 \\
\hline & Abril & 2 & 39 & 41 \\
\hline & Mayo & 3 & 4 & 7 \\
\hline & Julio & 28 & 75 & 103 \\
\hline & Agosto & 27 & 13 & 40 \\
\hline & Septiembre & 2 & & 2 \\
\hline Total & & 166 & 262 & 428 \\
\hline
\end{tabular}

Tabla 2

Número de personas fallecidas y personas desaparecidas en la ruta atlántica según mes y año entre 2019 y 2020 .

\section{Fuente}

Elaboración propia a partir de los datos de Missing Migrant Project.

Según los datos de la Organización Internacional de las Migraciones a través de su proyecto Missing Migrant Project (MMP), desde el 1 de enero de 2019 hasta el 22 de septiembre de 2020 se han contabilizado 27 naufragios en la ruta marítima hacia Canarias, con un total de 428 personas fallecidas o desaparecidas, de las cuales 185 tuvieron lugar en 2019 y 243 en 2020 (tabla 2). A pesar de desconocer el perfil sociodemográfico de la

3 Vélez (2012) identifica algunos de los principales puntos de salida de los distintos itinerarios marítimos que se pueden seguir en la conocida como ruta atlántica. De norte a sur, bordenado el litoral africano, podemos señalar los siguientes: Tarfaya, en Marruecos; El Aaiún,Cabo Bojador, Dakhla y Güera, en los territorios del Sáhara Occidental; Nouadhibou, Cabo Blanco y Nouakchott, en Mauritania; Saint Louis, Kayar, Dakar, Mbour y la zona sur de Casamance, en Senegal; Barra y Gunjur, en Gambia. En el caso de Marruecos, se podrían añadir también Tan Tan y Sidi Ifni en sentido septentrional. 
mayoría de las personas que protagonizaron los naufragios, se ha podido documentar el fallecimiento de al menos 7 menores de edad.

Hay que recordar que, a pesar de los esfuerzos para documentar las muertes a lo largo de las rutas migratorias, existen fuertes indicios de que muchas más personas han desaparecido sin dejar rastro mientras intentaban llegar a España. Las ONG que operan en España y en diferentes países africanos han recibido muchos informes adicionales de familiares de personas desaparecidas en naufragios, pero no pudieron confirmarse y el MMP no registra ninguna de estas muertes o desapariciones. Por ejemplo, la ONG Caminando Fronteras ha contabilizado, solo en el primer trimestre de 2020, 12 naufragios en la ruta hacia Canarias con un total de 245 víctimas.

El riesgo que se corre en una travesía marítima está determinado por diversos factores que, a su vez, interactúan los unos con los otros: a) entre los condicionantes físico-ambientales se debe hacer mención al estado de la mar (oleaje, corrientes), las condiciones meteorológicas (temperatura, vientos, sol, visibilidad) y la distancia (duración de la travesía); b) entre los relacionados con los recursos utilizados destacan la embarcación (aptitud para resistir condiciones adversas, capacidad de carga), el conocimiento de las técnicas de navegación (patrón experimentado), la motorización (fiabilidad, potencia, velocidad de travesía) y la conectividad comunicativa (aviso para petición de salvamento); c) la probabilidad de rescate por parte de otras embarcaciones, sean de servicios de salvamento o no, más la supervisión de la superficie marítima a distancia por aviones u otros medios tecnológicos.

Casi la totalidad de las personas embarcadas tiene nula o escasa experiencia en la mar, están expuestas durante la travesía a condiciones adversas (hacinamiento, escasez de agua y alimentos, exposición a los elementos) y son vulnerables (niños y niñas, mujeres embarazadas, personas debilitadas por el trasiego anterior). Además, un porcentaje no menor de las personas que inician la misma desconocían previamente los detalles de la travesía, lo que indica que la canalización de estos grupos funciona con bajos niveles de transparencia y previsilidad de los acontecimientos posteriores. En este contexto, las estrategias para soslayar la incertidumbre recurren principalmente a la comunicación: avisar de las expediciones a parientes y amistades, llamadas a teléfonos de urgencia, contacto con ONG, etc.

\section{La recepción en destino}

La recepción de las embarcaciones que llegan al archipiélago con personas inmigrantes a bordo supone un proceso complejo porque diversa es su expresión, dado que la forma de acceso no es siempre la misma y a lo largo del tiempo ha ido mostrando distintas manifestaciones. A las originales pateras se sumaron más tarde los cayucos y hasta ha aparecido por las costas canarias algún navío mercante destartalado de mayor calado, incluso lanchas neumáticas en este último repunte migratorio. Puntos de salida, itinerarios y condiciones ambientales, también influyen en la variabilidad de situaciones que se pueden encontrar (Vélez, 2015).

Las embarcaciones pueden ser interceptadas en alta mar o cerca del litoral insular a través del Servicio Marítimo de la Guardia Civil o de Salvamento Marítimo, bien en misiones de búsqueda o alertados por otros barcos o aeronaves. Algunas llegan por sus propios medios a los puertos más próximos y no es infrecuente que arriben a alguna playa accesible, aunque también se han dado casos, con tragedias incluidas, de encuentro con las islas en 
lugares poco propicios y enormemente peligrosos para el acceso a tierra. Incluso pueden encontrarse a la deriva con todo o parte de su pasaje ya fallecido.

Por otra parte, la recepción implica a muchas personas y colectivos de distintas entidades, organizaciones e instituciones, variando la logística en función de la forma y lugar de acceso y hasta del número de personas que llegan en la expedición, considerando además su estado de salud, así como de las que puede haber en ese momento en los puntos de recibimiento fruto de llegadas previas. Todo ello se ha complicado en los últimos meses en el contexto de la pandemia por coronavirus, en prevención de que en las embarcaciones se encuentren personas portadoras del SARS-CoV-2.

\subsection{Primera etapa: contacto inicial y atención sanitaria}

Como ya se ha señalado, las embarcaciones con personas migrantes que pretenden navegar hasta el archipiélago canario pueden conseguir su propósito de diversas maneras. Con mayor frecuencia son interceptadas antes de acercarse a las costas insulares, incluso a mucha distancia de las mismas, por los recursos de Salvamento Marítimo, que dispone de dos Centros de Coordinación en los recintos portuarios de Las Palmas de Gran Canaria y Santa Cruz de Tenerife. O también por las patrulleras de la Guardia Civil, que tienen como misión el control de la inmigración irregular en las aguas marítimas españolas.

Dependiendo de la operativa, ambas organizaciones pueden coordinarse para realizar el rescate, siendo resultado habitualmente de la actividad de detección de los radares del SIVE (Sistema Integrado de Vigilancia Exterior), instalados en las islas de Fuerteventura y Lanzarote. Las detecciones son producto a veces de la labor del SAR o Servicio Aéreo de Rescate del Ejército Español, radicado en la base aérea de Gando en la isla de Gran Canaria, que también ha efectuado labores de evacuación de personas con un precario estado de salud, incluso de lanzamiento desde el aire de balsas salvavidas cuando las circunstancias lo demandan.

Cada vez son más habituales las llamadas de aviso de distintas ONG con actividad en las áreas de origen, que son contactadas por personas que han sido conocedoras de la salida de alguna expedición o informadas por las propias inmigrantes que las integran, incluso desde las embarcaciones cuando existe cobertura telefónica y a veces en situaciones muy comprometidas. Con frecuencia se recaba la colaboración del tráfico marítimo que se encuentra en la franja meridional de Canarias para que colabore en el acompañamiento de las embarcaciones, hasta que llegan los recursos de rescate; son esos navíos los que en muchos casos comunican la presencia de pateras, cayucos o lanchas neumáticas surcando el océano.

En el marco de este último episodio migratorio han sido muchas las voces que han cuestionado la operatividad del SIVE, sobre todo al reiterarse las llegadas directas al litoral de la mayor parte de las islas, incluida la occidental de La Palma. Desde el Centro de Coordinación Regional de Canarias (CCRC), del que depende este sistema, se suele argumentar la complejidad de su trabajo por la extensa superficie marítima que deben rastrear y la dificultad en la detección a causa del reducido tamaño de muchas embarcaciones, que se pueden confundir con el oleaje, según declaraciones de sus responsables a distintos medios de comunicación regionales.

En otros casos, las embarcaciones tocan tierra por sus propios medios y las personas inmigrantes bien permanecen en el lugar o se dispersan inmediatamente al llegar. Hasta allí, 
alertados en muchos casos por la vecindad o personas transeúntes, acuden efectivos de las Fuerzas y Cuerpos de Seguridad del Estado incluyendo la Policía Local. También concurren Cruz Roja y recursos sanitarios movilizados por el Centro Coordinador de Emergencias y Seguridad 112 (CECOES) implicando al Servicio de Urgencias Canario (SUC). En el segundo caso de huida, se organiza un dispositivo de búsqueda en la zona.

Los cuerpos policiales correspondientes activan el Protocolo de Coordinación y Colaboración de la Comunidad Autónoma de Canarias, una de las consecuencias de la crisis de los cayucos (2006) para hacer frente a este tipo de inmigración, que plantea "la estrecha coordinación de todos los organismos relacionados y medios disponibles, tanto en el ámbito marítimo, aéreo, como terrestre, que se empleen para afrontarla" (Orden PRE/3108/2006) y cuya manifestación fue la creación del Centro de Coordinación Regional de Canarias, antes citado, cuya sede de operaciones está radicada en Las Palmas de Gran Canaria.

La llegada a puerto con aviso previo activa el habitual dispositivo de atención humanitaria a inmigrantes de Cruz Roja (ERIE), en el que se implica el personal de esta organización junto a su voluntariado. El hospital de campaña comprende el módulo de reconocimiento y asistencia sanitaria, realizándose en otros espacios el cambio de ropa, aprovisionamiento de agua y bebidas calientes y primeros alimentos. También se lleva a cabo una identificación básica: nombre, edad y procedencia. En caso de detección de situaciones graves o embarazos se producen traslados a recintos hospitalarios. En este punto se separa a hombres, mujeres y menores, a no ser que se identifiquen vínculos familiares. Se procura asimismo identificar a mujeres víctimas de trata y violencia de género.

El contexto de pandemia y la necesidad de realizar test PCR a las personas que llegan en cada expedición requiere la incorporación de un protocolo especial, que se aplica tras la filiación que efectúa la Policía Nacional; los datos recabados y la asignación de una identificación son fundamentales para que desde atención primaria del Servicio Canario de Salud se puedan hacer las pruebas correspondientes, bien en los propios muelles o en las naves habilitadas en los recintos portuarios.

El ascenso migratorio ha obligado a buscar fórmulas para acoger a un número importante de personas inmigrantes que se concentran en poco tiempo, derivando incluso en la habilitación de improvisados campamentos o naves industriales en los mismos recintos portuarios, soluciones bastante cuestionadas desde múltiples instancias cuando la permanencia de estas personas se prolonga más del tiempo deseable y hasta legalmente establecido. Esto ha ocurrido, por ejemplo, en el puerto de Arguineguín del municipio de Mogán en el sur de Gran Canaria, en el que se han llegado a concentrar más de 400 personas inmigrantes bajo tiendas o carpas en las que se separa a las que han protagonizado cada expedición. O en el puerto de La Luz en Las Palmas de Gran Canaria, donde se habilitó una nave dedicada al almacenaje para alojar distintas expediciones desde la primavera de 2020. También existe otra nave acondicionada en el recinto portuario de Puerto del Rosario en Fuerventura.

Coincidiendo con el aumento de las cifras de llegadas y las dificultades añadidas por la pandemia, se han planteado distintas alternativas mediante la instalación de un campamento o centro operativo con más capacidad, consistencia y servicios en el área portuaria de Arinaga en el este de Gran Canaria, finalmente no construido por falta de acuerdo institucional. Hacia ese mismo lugar, pero en otras instalaciones (residencia escolar de la playa del Cabrón), se viene derivando a las personas que reciben un resultado positivo de 
las pruebas COVID-19 (solo el 2 o 3\% de las realizadas, según señalan responsables del dispositivo de recepción), donde continúan la cuarentena en aislamiento. Las personas con resultado negativo pero que han mantenido contacto estrecho con las anteriores, pasan su cuarentena en otro centro de la localidad de Tunte (San Bartolomé de Tirajana). Y aquéllas con el mismo resultado y sin contactos con positivos son alojadas en albergues o instalaciones hoteleras, dado que los $\mathrm{CIE}$ han permanecido cerrados durante buena parte del año 2020.

\subsection{Segunda etapa: Identificación y tramitación administrativa}

Tras la intervención de Cruz Roja y junto a los recursos sanitarios regionales, la Policía Nacional se encarga de los trámites iniciales, comunicando la detención de las personas inmigrantes a distintos departamentos del Gobierno del Estado en el área de Extranjería y a la propia Delegación del Gobierno en Canarias. Se cumplimenta además el 'Documento Litoral' con la información sobre el número de ocupantes, tipo y características físicas de la embarcación, lugar de origen y desembarque, filiación y nacionalidad de las personas que vienen al cargo de la expedición o patrones, etc.

Se realiza la lectura de los derechos a las personas migrantes informándoles además de su derecho a la asistencia sanitaria y jurídica — siendo fundamental aquí el papel de intérpretes-, remitiendo los originales firmados al juzgado correspondiente. También se toman fotografías de las personas en su calidad de detenidas y se registran sus huellas dactilares. En caso de que la o el inmigrante sea identificado, se le comunica que va a ser retornado a su país de origen, algo que se ha tenido que interrumpir en los últimos meses a causa del cierre de fronteras por los efectos de la pandemia, pero que se podría activar en breve plazo apelando a los acuerdos específicos de readmisión o los acuerdos marco de cooperación que el Estado ha suscrito con distintos países africanos: Marruecos, Argelia, Guinea-Bissau y Mauritania, en el primer caso; Gambia, Guinea y Cabo Verde, en el segundo.

Esta detención a efectos de expulsión se traslada al consulado correspondiente, al que se facilitarán los datos sobre la personalidad del extranjero y la medida de internamiento adoptada. Si no se puede notificar al consulado o éste no está radicado en algún punto del país, la comunicación se dirige al Ministerio de Asuntos Exteriores. Si la persona inmigrante lo solicita, se pondrá en conocimiento de sus familiares residentes en España la medida de internamiento, que según la legislación vigente no podrá superar los 60 días.

En etapas de menor intensidad migratoria, desde los recintos portuarios u otras áreas de recepción, las personas inmigrantes eran trasladadas directamente a los Centros de Estancia Temporal para Inmigrantes (CETI), en los que pueden permanecer hasta 72 horas. Se trata de dispositivos de primera y provisional acogida destinados a ofrecer servicios y prestaciones sociales básicas a las personas inmigrantes y solicitantes de asilo, en tanto se realizan los trámites de identificación y revisión médica previos a cualquier decisión en relación con su futuro en el país.

Se ha producido alguna experiencia de utilización de los CETI, aunque en régimen abierto, a partir de la salida de estas personas de los CIE tras los 60 días de estancia máxima cuando estos estaban en funcionamiento. Existen CETI en Playa de las Américas (Arona, Tenerife) y en Las Palmas de Gran Canaria. También en distintas oportunidades se han habilitado más espacios temporales de este tipo en éstas y otras islas, acondicionando instalaciones provisionales y más bien precarias en determinados casos. 


\subsection{Tercera etapa: Desenlaces y recorridos diversos}

Durante las primeras fases ya planteadas se va organizando a las personas que llegan en cada expedición, puesto que, en virtud de su edad, circunstancias de salud, posibilidades de identificación, demanda o no de asilo, etc., incluso decisión de derivación desde el archipiélago a otros puntos del país, seguirán uno u otro itinerario o se vincularán con un recurso determinado en Canarias, desde los CIE hasta los centros de acogida humanitaria y centros de menores, entre otros.

La pandemia ha alterado en buena medida esta secuencia, dado que los CIE, por ejemplo, interrumpieron su funcionamiento durante varios meses a partir de abril al producirse contagios entre sus ocupantes y el personal dedicado a su gestión, además de no poder materializarse las expulsiones o devoluciones hacia sus países de origen. Ese cierre se produjo además en el contexto de una creciente controversia acerca de su propia existencia y funcionamiento, acumulando un número importante de denuncias en relación con sus múltiples carencias. Sin embargo, la intensificación de la afluencia y la debilidad de un sistema de recepción que diera plena respuesta al número de personas llegadas, ha derivado en la reapertura de los que se encuentran en las islas capitalinas.

Cabe recordar que los $\mathrm{CIE}$ son establecimientos públicos no penitenciarios adscritos al Ministerio del Interior bajo la responsabilidad del Cuerpo Nacional de Policía, destinados a la custodia preventiva o cautelar de personas extranjeras para garantizar su expulsión o devolución. De los 8 existentes en España, tres se localizan en Canarias: Barranco Seco, en Las Palmas de Gran Canaria; Hoya Fría, en Santa Cruz Tenerife; y El Matorral, próximo al aeropuerto de Fuerteventura, cerrado desde 2018. A ellos habría que sumar las instalaciones aeroportuarias de Lanzarote.

En el caso de las personas menores de edad que viajan sin el acompañamiento o cuidado de una persona adulta, y tomando como presunción la minoría de edad, se ponen a disposición de los servicios competentes de Protección de Menores. Se solicita judicialmente su incorporación en el Programa de Acogida Inmediata de Menores Extranjeros no Acompañados, validándose su condición de menor a través de las pruebas médicas que determinarán sus edades (grado de maduración ósea o dental). Su tutela corresponde al Gobierno de Canarias, delegada en los Cabildos insulares, que disponen de centros en el marco de una red de acogida estable o habilitan dispositivos de emergencia. Su estancia se considera regular a todos los efectos.

En relación con las mujeres llegadas por vía marítima, caben tres supuestos. En el caso de mujeres embarazadas, quedará en suspenso la resolución de devolución cuando la medida pueda suponer un riesgo para la gestación o para la salud de la madre. En cuanto a las mujeres que llegan solas o con hijos e hijas menores, considerando las circunstancias de vulnerabilidad que sufren durante su salida y tránsito -y potencialmente también en las áreas de recepción-, no se suele solicitar autorización judicial para su internamiento en el $\mathrm{CIE}$, porque en buena medida estos centros no están habilitados para ellas y porque en algunas oportunidades no cabe su devolución. Y en ese caso, son acogidas por Cruz Roja a través del programa de atención humanitaria de la Secretaría de Estado de Migraciones.

También se presta una atención especial a la existencia de posibles víctimas de trata o tráfico de personas, violencia de género o de cualquier otro delito. Teniendo en cuenta la complejidad de este tipo de asistencia y que lleva tiempo que pueda ser identificado o revelado con certeza, se procura favorecer el trabajo en red de todos los agentes implicados en la gestión de esta afluencia migratoria. Tanto durante la fase de identificación 
de las víctimas como durante el periodo de restablecimiento y reflexión (hasta 90 días en caso de trata), se suspenderá la ejecución de la expulsión o devolución eventualmente acordada por el órgano judicial correspondiente, velando la administración por la subsistencia, seguridad y protección de la víctima y de sus hijos e hijas menores de edad o con discapacidad.

La reciente aplicación de una sentencia del Tribunal de Justicia de la Unión Europea que facilita la demanda de protección internacional por motivos fundamentados, parece anunciar un profundo cambio en cuando a la posibilidad de internamiento y pronta devolución de las personas cuya solicitud de asilo sea admitita a trámite. Esto implica que se les deba asignar una plaza de primera acogida humanitaria en régimen abierto por parte del Ministerio del Interior, gestionadas en Canarias por la Comisión Española de Ayuda al Refugiado (CEAR) o Cruz Roja, lo que supone la cobertura de sus necesidades básicas y su alojamiento en hostales o espacios comunitarios disponibles — tanto en el archipiélago como en la Península - el tiempo máximo de nueve meses prorrogable otros seis. Se trata de un programa con vocación inclusiva, que también ofrece formación ocupacional de cara a la promoción personal de inmigrante.

\section{Retos y perspectivas}

Ante lo expuesto, parece que todavía hoy, pese a los esfuerzos realizados y "tras más de dos décadas de llegadas de pateras a las costas españolas, sigue sin existir un modelo coherente, coordinado y compartido sobre cómo gestionar este fenómeno en todo el territorio nacional" (González Beilfuss, 2019: 167). Además, la reactivación de la ruta atlántica a través de las Islas Canarias muestra que se está repitiendo un patrón previo y que era previsible que volviera a manifestarse cuando confluyeran circunstancias como las ya descritas (Godenau, 2019: 161).

Este nuevo episodio de intensificación tiene varios elementos en común con el anterior acaecido durante la primera década del siglo XXI: primero, se trata de un fénomeno inducido por cambios en la permeabilidad de otros lugares de la frontera europea, particularmente en la ruta del Mediterráneo Occidental; segundo, se observa una evolución por fases durante las que se trasladan los puntos de salida en la costa africana, con un progresivo aumento de las distancias marítimas con Canarias y el correspondiente riesgo para las personas migrantes; tercero, el incremento en las llegadas de nuevo revela un sistema de acogida que se reactiva a remolque de los acontecimientos, con las correspondientes consecuencias negativas para las personas afectadas; cuarto, también se repiten las reacciones discursivas extrapunitivas y de alarma que reclaman mayor atención a las instancias nacionales y supra-nacionales; quinto, se retoman las políticas exteriores de contención de las salidas del continente africano a través de acuerdos bilaterales; sexto, las tan repetidas recomendaciones de promover el desarrollo económico de los países de origen para reducir el potencial emigratorio no han tenido consecuencias efectivas.

Pero la nueva etapa de intensificación en el uso de esta ruta también trae consigo algunos elementos originales, entre los cuales hay que destacar aquellos relacionados con el contexto de la actual crisis sanitaria y socioeconómica: por un lado, es un factor añadido de inestabilidad en los países emisores y de incertidumbre en las áreas de tránsito; por el otro, implica la necesidad de llevar a cabo pruebas PCR a las personas recién llegadas, la gestión de espacios de aislamientos grupales y la imposibilidad de devolución a los países de origen o de embarque, lo que influye significativamente en las tres etapas descritas 
en los párrafos anteriores. Otra diferencia es que en los últimos años se ha desactivado el plan de traslado que permitía a numerosas personas inmigrantes en situación administativa irregular seguir su periplo migratorio hacia el continente europeo.

Un tercer elemento diferencial con respecto a 2006 es que, actualmente, las redes sociales tienen un mayor impacto en el discurso público que hace quince años. Por un lado, hay que tener en cuenta la amplia difusión del discurso del odio on-line, que representa un peligroso caldo de cultivo para el racismo y la xenofobia; por el otro, la llegada de personas migrantes está siendo mediatizada no solamente por los medios de comunicación tradicionales, como la televisión, la radio o la prensa, sino también por numerosas personas que graban imágenes de la llegada de las embarcaciones, añadiendo comentarios despectivos, violentos y discriminatorios. Estos videos, fotografías, memes, etc., pueden tener una amplia difusión en las redes sociales y el peligro añadido de poder representar, para quien las visualiza o las lee, una fuente de información aparentemente fiable, porque es generada por personas de aquí, que hablan desde la experiencia personal y que se muestran indignadas y frustradas. Esta dinámica se agrava en el presente contexto de incertidumbre sanitaria y económica, pudiendo incidir negativamente en las actitudes hacia la inmigración.

Y en medio de todo esto, se sitúa el ineludible objetivo de garantizar los derechos de las personas inmigrantes en el complejo y cambiante contexto de crisis sanitaria: la asistencia legal efectiva, la atención médica y el respeto de las medidas de prevención sanitaria necesarias, el acceso a la solicitud de asilo, etc. Aspectos que pasan por lograr un positivo diálogo y coordinación entre el amplio conjunto de actores implicados en la gestión de los procesos migratorios a distintos niveles, así como la asignación de los recursos y medios necesarios, tal y como se ha demandado recientemente desde el Foro Canario de la Inmigración.

En su última sesión de trabajo ${ }^{4}$, manifestó su "preocupación por la carencia de medios para la atención adecuada a las personas que están llegado a Canarias", así como por el incremento de naufragios y la pérdida de vidas humanas, más la proliferación de discursos xenófobos y la exaltación del odio, dirigiendo sus demandas a las instituciones europeas, estatales y regionales. "También cabe mejorar la intervención y la aportación que se realiza desde el propio archipiélago y la imprescindible implicación social, aprovechando los aprendizajes obtenidos y los recursos existentes, como fórmula para que la gestión de las migraciones en el marco de nuestra región se convierta en un modelo de referencia, tanto hacia los procesos de desarrollo internos como hacia nuestra consideración y proyección exterior".

Esta claro que lo que desactivará las llegadas son consistentes políticas exteriores a desplegar en África en colaboración estrecha con los territorios de origen y tránsito migratorio, tanto en su definición como en su aplicación y evaluación, con perspectiva de largo plazo e incidencia real en sus procesos de desarrollo, enfocadas a la minimización de los factores ya enunciados que promueven los flujos migratorios. Se trata de un fenómeno social conocido y gestionable, no de una catástrofe natural repentina, que se debe atender de manera permanente porque siempre habrá propensión a que se pueda amplificar de una u otra forma, a veces, como está ocurriendo en esta oportunidad, en el marco de una situación excepcional que ha complicado todavía más su gestión. Ante ello, anticipación y planificación.

4 El Foro Canario de la Inmigración dedicó una sesión monográfica al tema de la inmigración irregular por vía marítima el 9 de septiembre de 2020, aprobando por unanimidad un documento de conclusiones y demandas dirigido al Gobierno de Canarias, al Estado Español y a la Unión Europea [https://www3.gobiernodecanarias. org/noticias/wp-content/uploads/2020/09/Conclusiones-Foro-09.9.20.pdf] 
Para ampliar la información

CVAJNER, M. y SCIORTINO, G. (2010). Theorizing irregular migration: the control of spatial mobility in differentiated societies. European Journal of Social Theory, 13(3), 389-404.

DE GENOVA, N. (2002). Migrant "Illegality" and deportability in everyday life. Annual Review of Anthropology, 31(1), 419-447.

DE GENOVA, N. (2004). The legal production of Mexican/migrant "illegality". Latino Studies, 2(2), 160-185.

DÜVELL, F. (2011). Paths into irregularity: The legal and political construction of irregular migration. European Journal of Migration and Law, 13(3), 275-295. https://doi. org/10.1163/15718 1611X587856

ECHEVERRÍA, G. (2020). Towards a Systemic Theory of Irregular Migration: Explaining Ecuadorian Irregular Migration in Amsterdam and Madrid. Springer Nature.

GODENAU, D. (2012). An Institutional Approach to Bordering in Islands: The Canary Islands on the African-European Migration Routes. Island Studies Journal, Vol. 7, No. 1, 3-18.

GODENAU, D. (2019). Canarias: lugar de llegada y tránsito de la ruta migratoria atlántica hacia Europa. El fenómeno migratorio en España. Reflexiones desde el ámbito de la Seguridad Nacional, Gobierno de España, 155-161.

GONZÁLEZ BEILFUSS, M. (2019). Migración irregular en España. Mediterráneo, Canarias y Ciudades Autónomas. El fenómeno migratorio en España. Reflexiones desde el ámbito de la Seguridad Nacional, Gobierno de España, 163-167.

LÓPEZ SALA, A. y GODENAU, D. (2017). Delegando el control migratorio. Una aproximación a las dinámicas del outsourcing en España. En A. López Sala y D. Godenau (coords.), Estados de Contención, Estados de Retención. El control de la inmigración irregular en España. Barcelona: Anthropos, 197-223.

OIM (2006). Glosario de las migraciones. Ginebra: Organización Internacional para las Migraciones (OIM).

VÉLEZ ALCALDE, F. J. (2015). La inmigración irregular por vía marítima hacia Europa del Sur. La respuesta de los Estados, Tesis Doctoral (inédita), UNED.

Para la realización de este trabajo se han consultado diversos artículos periodísticos publicados en formato digital por la prensa regional en Canarias durante el año 2020. Los autores desean expresar su agradecimiento a José Antonio Rodríguez (Cruz Roja) y Txema Santana (CEAR), por sus aportaciones para la caracterización del proceso de recepción en destino. Asimismo se han consultado diversos informes de OBITen sobre inmigración irregular por vía marítima realizados por Amal Belleyo Belkasem y Loueila Mint El Mamy. 


\section{Cómo citar este artículo:}

GODENAU, D., BURASCHI, D. y ZAPATA HERNÁNDEZ, V.M. (2020). Evolución reciente de la inmigración marítima irregular en Canarias. OBITen Factsheet 8-2020. Recuperado de www.obiten. net. DOI: https://doi.org/10.25145/r.obitfact.2020.05.

El Observatorio de la Inmigración de Tenerife es una iniciativa conjunta del Cabildo de Tenerife y la Universidad de La Laguna que surge con vocación de estructura permanente y dinámica para avanzar en el conocimiento científico de los movimientos migratorios. OBITen desarrolla su actividad a modo de centro de recopilación, producción y difusión de información que facilita la opinión cualificada y favorece la toma de decisiones que redunden en una mejor gestión del fenómeno inmigratorio y sus implicaciones.

\section{http://www.obiten.net}

